\title{
A mediação da informação no resgate da visibilidade e dignidade dos vulneráveis: o caso das pessoas em situação de rua
}

\author{
Tânia Regina de Brito \\ Doutoranda; Universidade Estadual Paulista "Júlio de Mesquita Filho", Marília, SP, Brasil; \\ tania.brito@unesp.br \\ Regina Célia Baptista Belluzzo \\ Doutora; Universidade Estadual Paulista "Júlio de Mesquita Filho”, Marília, SP, Brasil; \\ rbelluzzo@gmail.com \\ Oswaldo Francisco de Almeida Junior \\ Doutor; Universidade Estadual Paulista “Júlio de Mesquita Filho”, Marília, SP, Brasil; \\ oswaldo@ofaj.com.brl
}

\begin{abstract}
Resumo: A mediação da informação é abordada sob a perspectiva da vulnerabilidade social, considerando-se como sujeitos informacionais as pessoas em situação de rua. Questiona-se se tal população, ainda que não tenha as suas necessidades básicas atendidas pelo governo, terá a sua voz ouvida por profissionais da informação. Assim, tem como objetivo refletir acerca da mediação da informação enquanto promotora no resgate da cidadania e dignidade das pessoas vulneráveis, num ambiente de bibliotecas públicas. Trata-se de estudo com abordagem qualitativa, a partir de pesquisa bibliográfica realizada em catálogos de bibliotecas universitárias e do Portal de Periódicos da Capes, envolvendo temáticas, como: mediação da informação, vulnerabilidade social, pessoas em situação de rua, competência em informação e biblioteca pública. Entendida como um processo que, junto com a competência em informação, tem potencial transformador para munir as pessoas para o empoderamento informacional, podendo minimizar a condição de miséria e, sobretudo, as múltiplas vulnerabilidades a que são expostas. Compreende-se que os profissionais da informação de bibliotecas públicas são mediadores capazes de contribuir para que aos vulneráveis, que recorrem a esses espaços, possam dar voz às suas necessidades informacionais, possibilitando-lhes, assim, mesmo que por um curto período e por motivos diversos, viver o sedentarismo que não conseguem. Em espaços como a biblioteca pública, a presença da mediação da informação contribui para o avanço de uma sociedade com habilidades informacionais, a fim de formar cidadãos mais críticos e cônscios de sua importância no mundo.
\end{abstract}

Palavras-chave: Mediação da informação. Pessoas em situação de rua. Competência em informação. Vulnerabilidade social. 


\section{Introdução}

A mediação da informação, no contexto da Ciência da Informação, dialoga com áreas como a educação e a cultura, e vem, ao longo dos anos, ampliando e aprimorando suas bases teóricas. Surge da reflexão sobre uma lacuna teórica presente no Serviço de Referência e Informação que, apesar da sua significância no campo da Biblioteconomia - por envolver a educação e o processo de interação do usuário-informação, exigia tempo e espaço para acontecer, permanecendo de uma maneira geral na oferta de materiais e se limitando a ambientes estritamente físicos (ALMEIDA JÚNIOR, 2015).

Assim, a importância que a educação e a cultura têm no desenvolvimento dos sujeitos, garantindo a construção de sua autonomia e do seu espírito crítico e, por consequência, a transformação da realidade que os cerca e considerando que esses aspectos se constituem em "locus da mediação da informação" como afirma Gomes (2014, p. 48), tem-se a mediação e todos os agentes envolvidos no processo da mediação, como protagonistas ou potenciais colaboradores do protagonismo social. A biblioteca é um dos espaços em que a mediação se encontra a priori, podendo mediar as necessidades de seus usuários - ou interagentes, termo requerido por Corrêa (2014).

Neste artigo, a mediação da informação é abordada num contexto de vulnerabilidade social, considerando-se como sujeitos informacionais as pessoas em situação de rua, população que se encontra, salvo circunstâncias pontuais, em situação de invisibilidade pelo poder público e pela sociedade em geral.

Desse modo, questiona-se se tal população, além de não ter suas necessidades básicas - tais como moradia, trabalho, alimentação, dinheiro e saúde (LINN; GELBERG, 1989) - atendidas pelo governo, não terá a sua voz ouvida por profissionais da informação. Se ouvidas, serão suas necessidades informacionais satisfeitas? Quais são essas necessidades? De acordo com Almeida Júnior (2015, p. 26), a “[...] mediação da informação diz respeito à satisfação informacional do usuário". Muito embora tal satisfação seja parcial e momentânea, ela visa à apropriação da informação por essas pessoas.

Outrossim, a apropriação ora mencionada pode gerar o desenvolvimento 
integral do sujeito, a construção do conhecimento e os mecanismos geradores de sentidos, sendo diretamente ligada à presença da mediação da informação em ações que favorecem a prática de processos cognitivos, comunicacionais e sociais.

Ainda para Almeida Júnior (2015), a informação, embora se perpetue e se embrenhe no conhecimento, é sempre efêmera, apesar de concreta. Isso porque, no entendimento desse autor, quando apropriada, a informação se reconstrói, ou como em suas palavras, "ela morre ainda se construindo". O mesmo autor também defende a ideia de que a informação precisa ser, portanto, mediada, não se limitando a sua transferência ou disseminação e ficando sempre estabelecida uma relação de diálogo no processo de mediação da informação (ALMEIDA JÚNIOR, 2015).

A rua é o espaço ocupado por uma parcela da população que vive na extrema pobreza, também chamada de pessoas em situação de rua, cujo acesso e relação com as informações têm sido prejudicados na sociedade. Assim, neste artigo, busca-se como objetivo geral, refletir acerca da mediação da informação enquanto promotora no resgate da cidadania e dignidade das pessoas vulneráveis, em especial aquelas em situação de rua. Outrossim, compreendendo cidadania como o direito das pessoas à vida em sentido amplo, em seus direitos e deveres civis, políticos e sociais e, portanto, uma categoria estratégica para uma sociedade melhor (CERQUIER-MANZINI, 2013).

Além disso, leva-se em conta o processo da competência em informação, pois uma vez mediada a necessidade informacional, os sujeitos precisam estar preparados para o domínio do universo informacional. Ou seja, haverá de ser esta uma mediação que oportunize um encontro entre as pessoas em situação de rua e sua visibilidade como pessoas e cidadãos; um encontro ou um resgate que lhes possibilite sonhar com uma realidade mais digna, já que vivem na vida pública as suas vidas privadas.

Ainda, quanto à competência em informação, cabe ressaltar que esta merece atenção primária e mobilização da Sociedade Civil Organizada, sobretudo quando as discussões ou ações orbitam em contextos de extrema vulnerabilidade social, em que as populações vulneráveis e as minorias vivem cotidianamente “[...] situações de discriminação, intolerância e fragilidade e que estão em 
desigualdade e desvantagem na sociedade atual" (MANIFESTO..., 2013, p. 1), como é o caso das pessoas em situação de rua.

\section{Aspectos metodológicos}

O trabalho tem uma abordagem de natureza qualitativa, pois se trata de pesquisa bibliográfica, realizada em agosto de 2019, decorrente de consultas em livros, artigos, teses e dissertações que contemplem as temáticas: mediação da informação, competência em informação, vulnerabilidade social e pessoas em situação de rua. Para tal, foram feitas buscas em catálogos de bibliotecas universitárias.

Também se recorreu ao portal de Periódico da Capes, onde foi realizada uma busca seletiva (busca por assunto), utilizando as palavras-chave em português: mediação da informação, competência em informação, vulnerabilidade social, pessoas em situação de rua, biblioteca pública. Em um primeiro momento, foram selecionados os textos a partir da análise do seu conteúdo (título e/ou resumo) que tivessem alinhamento e aderência à proposta da investigação.

A partir da leitura e da análise dos materiais bibliográficos recuperados, foram selecionados aqueles que mais se aproximassem ou pudessem contribuir com a temática, o que permitiu a sistematização de conceitos e de princípios teóricos. Isso nos possibilitou apresentar uma reflexão acerca da mediação da informação, associando-a à competência em informação, ambas como elementos com potencial transformador da realidade de pessoas vulneráveis.

\section{3 “O invisível” está na rua: você consegue enxergar?}

De acordo com a UNICEF (2017), pouco mais de $29 \%$ dos jovens ao redor do mundo, ou cerca de 346 milhões de pessoas, não estão conectadas on-line, apontando que o acesso desigual à internet aumenta o abismo da injustiça social. 
Caso fossem levadas em consideração demais faixas etárias da população mundial, esse número por certo cresceria vertiginosamente.

Em um país socialmente injusto, como no caso do Brasil, enquanto parcela da sociedade tem acesso, recursos - tecnológicos e cognitivos - para acessar a informação, tendo que lidar com o seu excesso; por outro lado, existem pessoas que apenas recentemente conquistaram uma política nacional em que foram reconhecidas por lei como cidadãos de direitos (BRASIL, 2009).

Referimo-nos às pessoas em situação de rua, que em virtude da vulnerabilidade, encontram-se num estado que se pode chamar de invisibilidade, já que são pontuais as iniciativas para a reflexão e a promoção do acesso à educação, à informação e à cultura para essa população. Sob tal perspectiva, evidencia-se que o reconhecimento dos mesmos “[...] ainda não é acolhido na sociedade" (BRASIL, 2014).

Vieira, Bezerra e Rosa (1994) identificam as principais situações em relação à população de rua como sendo, em síntese: (1) pessoas que ficam na rua: motivadas pela precariedade da vida, pelo desemprego ou por se deslocarem de sua região para outra cidade em busca de emprego, de tratamento de saúde ou outras situações. Nesses casos, costumam passar a noite em rodoviárias, albergues, ou locais públicos que possuem movimento, a fim de não correr "perigo"; (2) pessoas que estão na rua: indivíduos que não se sentem ameaçados nas ruas, em razão disso, passam a estabelecer relações com as pessoas que vivem na ou da rua, criando estratégia de sobrevivência; e (3) pessoas que são da rua: aquelas que se encontram instaladas nas ruas por período de tempo considerável e, em decorrência, foram sofrendo um processo de debilitação física e mental, especialmente pelo uso do álcool, das drogas ilícitas e em razão de violência.

Para esses autores,

[...] a população em situação de rua, geralmente está mais situada em centros urbanos, pois nessa área conseguem algum trabalho para a subsistência (catador de materiais recicláveis, por exemplo). Costumam se concentrar mais em áreas comerciais (centro da cidade), por haver maior chance de se conseguir doação de algum alimento ou obter algum dinheiro realizando trabalhos informais (guarda de carros, revenda de ingressos, venda de mercadorias, etc.). (VIEIRA; BEZERRA; ROSA, 1994, p. 95). 
Segundo o Decreto n. 7.053 de 2009, que instituiu a Política Nacional para a População em Situação de Rua (PNPSR), considera-se:

[...] população em situação de rua o grupo populacional heterogêneo que possui em comum a pobreza extrema, os vínculos familiares interrompidos ou fragilizados e a inexistência de moradia convencional regular, e que utiliza os logradouros públicos e as áreas degradadas como espaço de moradia e de sustento, de forma temporária ou permanente, bem como as unidades de acolhimento para pernoite temporário ou como moradia provisória. (BRASIL, 2009).

O decreto supracitado, além de prever a democratização do acesso e a utilização dos espaços públicos, visa ampliar, simplificar e assegurar serviços e programas que integram as políticas da educação, cultura, trabalho e outras que, acaso disponíveis, podem garantir as condições mínimas para uma pessoa exercer a sua cidadania quanto a esses aspectos.

Segundo Burton (2014), as chamadas políticas públicas são denominadas assim quando estão relacionadas com ações efetivadas pelo Estado, envolvendo, inclusive, atores ou mediadores diversos, tanto públicos quanto privados. Uma política voltada às pessoas em situação de rua também nos leva a refletir sobre as mudanças ocasionadas pela globalização e seus efeitos sobre o Estado. Santos (2005, p. 19) fala sobre a tirania da informação e do dinheiro, sendo ela caracterizada pelo pesquisador como o "caráter perverso atual" da globalização, posto que se constitui em "motor da vida econômica e social".

Entende-se que abordar a política em questão (PNPSR) também remete às políticas educacionais, tendo em vista que o documento que a institui abarca o citado aspecto educacional. Por exemplo, um dos objetivos da Política Nacional para a População em Situação de Rua visa:

[...] I - assegurar o acesso amplo, simplificado e seguro aos serviços e programas que integram as políticas públicas de saúde, educação, previdência, assistência social, moradia, segurança, cultura, esporte, lazer, trabalho e renda; (BRASIL, 2014).

Todavia, em pesquisas bibliográficas iniciais, não são encontradas ações que reflitam uma política educacional que de fato atenda essa população. Ao 
contrário, cita-se o trabalho de Almeida (2012, p. 1), o qual, após investigação, aponta

[...] as dificuldades enfrentadas por pessoas em situação de rua frente às possibilidades de retorno e continuação de sua escolarização, tais como: o fato de estar fora da escola há muito tempo pode favorecer a crença de que sabe menos por não possuir conhecimentos acadêmicos; estigma vivenciado cotidianamente por estar em situação de rua; não possuir condições materiais (roupas, material escolar etc.) para estar em ambientes escolares; possível dependência química; dentre outros.

Santos (2005, p. 59) expõe a situação precária em que sobrevivem as pessoas em situação de rua fazendo uma relação com a educação:

O fenômeno dos sem-teto, curiosidade na primeira metade do século $\mathrm{XX}$, hoje é fato banal, presente em todas as grandes cidades do mundo. O desemprego é algo tornado comum. Ao mesmo tempo, ficou mais difícil do que antes atribuir educação de qualidade e, mesmo, acabar com o analfabetismo.

A exclusão social no Brasil, além das origens econômicas, caracteriza-se pela falta do sentimento de pertencimento social, pelas perspectivas que são mínimas ou que não existem, pela perda de autoestima e dificuldade de acesso à informação, em que a pessoa excluída acaba tendo as oportunidades restritas no tocante à emancipação social (COSTA, 2005).

No I Censo e Pesquisa Nacional sobre População em Situação de Rua, realizado entre agosto de 2007 e março de 2008, em 71 cidades brasileiras, os motivos mais citados como causas que levaram tais pessoas a viverem em situação de rua são: problemas com alcoolismo/ou drogas $(35,5 \%)$, desemprego $(29,8 \%)$, desavenças com pai/mãe/irmãos (29,1\%) (CUNHA; RODRIGUES, 2009).

Atualmente, não existem dados oficiais sobre a população em situação de rua, recomendando-se que seja feita uma contagem no censo de 2020 pelo Instituto Brasileiro de Geografia e Estatística (IBGE) (NATALINO, 2016). Ainda de acordo com o IBGE (AGÊNCIA IBGE NOTÍCIAS, 2020), a realização desse censo foi adiada para 2021, inclusive em virtude da pandemia de Covid-19, o que vem reforçar essa situação. Contudo, números obtidos em cadastros de programas sociais do Governo Federal e prefeituras dão uma ideia de que, em 2015, esse 
quantitativo encontrava-se em torno de 101.854 pessoas. Como nem todas as prefeituras apresentam esses dados ou, levando-se em conta o fato de existirem pessoas que não têm cadastro nos sistemas de programas sociais, é provável que esse número, na atualidade, seja bem mais elevado (NATALINO, 2016).

Diante do exposto, questiona-se como as bibliotecas públicas, municipais ou estaduais, ao lado de centros de acolhimento, têm trabalhado no sentido de promover a mediação da informação para uma população que, em virtude de sua vulnerabilidade social, requer um tratamento no qual seja contemplado o resgate da cidadania e da dignidade, haja vista que tiveram a sua visibilidade subtraída? Estarão os profissionais dessas bibliotecas preparados para mediar informações para pessoas cujas "[ [... necessidades são geradas pelo pertencimento a um grupo, uma comunidade, uma tribo?" (ALMEIDA JÚNIOR, 2015, p. 27).

Nessa perspectiva, compreende-se ser necessário em bibliotecas nas quais são identificadas e sentidas as presenças de pessoas que fazem parte dos “invisíveis da rua", que o primeiro passo seja dar visibilidade às suas necessidades informacionais. Para tal, é necessário ouvir a voz dos "invisíveis", mediar suas necessidades informacionais para, posteriormente, propor ações ou programas que contemplem a competência em informação, esta, sendo entendida como um processo e se constituindo de "[...] atividades que objetivam desenvolver o senso crítico das pessoas em relação ao uso da informação" (BELLUZZO; SANTOS; ALMEIDA JÚNIOR, 2014, p. 67). Tais ações envolvem a utilização de abordagens didáticas, psicológicas e pedagógicas, além de dimensões, modelos, padrões e indicadores que são recomendados internacional e nacionalmente (ACRL, 2011, 2012; AUSUBEL, 1982; BELLUZZO, 2018; BRUCE, 2003; CATTS; LAU, 2008; FREIRE,2011; KUHLTHAU, 2018; VITORINO; PIANTOLA, 2011).

Tello (2008) apresenta diversos grupos vulneráveis levando em conta as fragilidades a que estão expostos, e que podem estar presentes em bibliotecas e centros de informação, ou pelos quais essas instituições podem trabalhar no sentido de facilitar o acesso aos serviços que oferecem. Segundo o autor: 
[...] los grupos vulnerables se definen como aquellos que se enfrentan a contingencias de deterioro, pérdida o imposibilid de obtener condiciones de oportunidades alimentarias, habitacionales, sanitrias, laborales, participativas, educativas y de acceso diferencial a la información, recurso que pueden y deben ofrecer de manera organizada las instituciones bibliotecarias de diverso género. (TELLO, 2008, p. 51).

Além disso, considera-se que compreender o sentido de vulnerabilidade e suas multidimensionalidades, pela atuação dos profissionais bibliotecários e da informação em geral, pode colaborar no sentido de compreender as necessidades informacionais manifestadas ou silenciadas por essas pessoas.

\section{A mediação da informação enquanto promotora [do resgate] da dignidade e da cidadania}

De acordo com Velho e Kuschnir (2001, p. 10), mediação “[...] é uma ação social permanente, nem sempre óbvia, que está presente nos mais variados níveis e processos interativos". Para os autores, mediadores são agentes de transformação, pois estabelecem comunicação entre grupos e categorias sociais diferentes, lidando com informações, acessos e credibilidades imprescindíveis para sua atuação (VELHO; KUSCHNIR, 2001).

Com um papel mediador relevante, bibliotecas públicas podem ser além de mediadoras das necessidades informacionais dos usuários, mediadoras das próprias necessidades de sobrevivência de pessoas em situação de rua que frequentam os seus espaços, estabelecendo-se um processo dialógico entre as pessoas em situação de rua consigo mesmas e/ou entre essas pessoas vulneráveis e o poder público. Além disso, os profissionais que atuam nesses espaços de bibliotecas têm como uma de suas responsabilidades a "educação/capacitação dos usuários para o acesso, avaliação e uso da informação", devendo "atuar junto às comunidades (populações vulneráveis e minorias) para produzir conteúdos informacionais sobre sua história, cultura e meio social" (MANIFESTO..., 2013, p. 2).

Como espaços de resistência, as bibliotecas públicas são um dos poucos territórios em que as pessoas em situação de rua tornam-se visíveis, seja porque, 
de alguma maneira, incomodam a sociedade por ter que dividir tal espaço público e seus equipamentos informacionais; seja porque, por um breve período do dia, elas podem ser contabilizadas como usuárias desses espaços; ou ainda porque deixam de ser "mais um" vagando ou dormindo por logradouros, praças ou calçadas, mesmo que durante curto período de tempo. Em outras palavras, é dizer que, nesses locais, essas pessoas se fazem percebidas.

Assim, o papel mediador de agentes públicos, como aqueles que atuam em bibliotecas públicas, em especial os bibliotecários, é debatido por Cunha (2003, p. 43) que afirma: “[...] nossa profissão é uma profissão essencialmente social, uma profissão de mediação e de contato, de 'fazer com o outro' de fazer para o outro". Aposta-se, assim, na ampliação de debates que contemplem a mediação da informação e, num segundo momento, a competência em informação para a efetivação da distribuição de saberes de maneira equilibrada, contribuindo para a formação de sujeitos social, cultural e intelectualmente autônomos. E, no caso das pessoas em situação de rua, isso é refletido sobretudo no resgate da cidadania e, por conseguinte, da dignidade desses grupos.

De acordo com Belluzzo (2018, p. 61):

Os impactos e benefícios das TIC na vida e no cotidiano da sociedade são inegáveis, entretanto, é sabido que muitos ainda estão à margem de uma utilização responsável e plena desses recursos, necessitando uma mediação adequada devido à complexidade imposta pela aquisição de novas habilidades e a necessidade da existência de políticas públicas que possam garantir verdadeiramente a "Informação para todos".

Para González de Gómes (2009, p. 107), as pessoas são consideradas como "[...] agentes e atores sociais cuja intervenção na produção, acesso ou uso de informação, afeta a vida de terceiros, por vezes na extensão indefinida de coletivos em redes". Nesse sentido, considerando também as menções de Aquino (2010), é possível afirmar que os agentes que compõem a biblioteca pública devem pensar sistematicamente em sua própria responsabilidade social, propondo ações de informação enquanto elementos de conscientização no combate à exclusão social. 
Desse modo, essas bibliotecas poderiam contribuir para a promoção de espaços de pluralidade na produção de novos conhecimentos, cidadania e na segurança para os grupos de pessoas, consideradas enfaticamente como sendo as minorias sociais, os grupos marginalizados em uma sociedade conservadora, em especial aquelas pessoas que se encontram em situação de rua.

Vale lembrar que Santos, Lima e Freire (2019), muito embora voltem seu olhares para as questões de mediação e de informação norteadas especificamente para pessoas LGBTI+, mencionaram a responsabilidade social da área de Ciência da Informação, que também pode se aplicar àquelas pessoas em situação de rua, salientando o que segue:

\begin{abstract}
Notamos que em sua trajetória histórica e teórica para estabelecimento como campo científico, a Ciência da Informação aponta a informação como um fenômeno social, que acompanha as transformações do mundo [...] Ou seja, a Ciência da Informação precisa voltar-se para a sociedade, e especificamente as minorias sociais, aqueles grupos marginalizados quanto ao acesso à informação, que se impõe como um direito fundamental para a inclusão e o exercício da cidadania. Nesse campo científico, a competência em informação pode estabelecer-se como norteadora de ações que combatam o preconceito e a desinformação e promovam a diversidade. (SANTOS; LIMA; FREIRE, 2019, p. 139).
\end{abstract}

Por outro lado, é possível exemplificar com uma realidade, embora de âmbito geográfico restrito, que foi noticiada por meio de jornais eletrônicos ${ }^{1}$, e que também pode ser observada in loco, onde a parcela da população em situação de rua que frequenta bibliotecas públicas usa o seu tempo "fora da rua" para acessar e utilizar os computadores disponibilizados à comunidade em geral. Não se tem conhecimento, contudo, sobre qual a finalidade ou as finalidades pelas quais essas pessoas acessam a internet. Assim, pergunta-se: para passar o tempo? Tão somente para aplacar a dor que muitos certamente sentem, a despeito de alguns escolherem assim viver? Alguma tentativa de conseguir uma ocupação? Aprimorar seus conhecimentos? São muitas perguntas e quase nenhuma resposta.

Em literatura que aborda outros tipos de populações que podem apresentar alguma similaridade com a população em situação de rua, como por exemplo daqueles que são denominados trecheiros ${ }^{2}$, encontramos a seguinte colocação de Nascimento (2008, p. 66): 
Sejam quais forem os motivos para a migração, a busca de melhores condições de trabalho parece ter condicionado, por muito tempo, a esperança interminável para as famílias desses sujeitos, pois boa parte delas acreditava no sonho de prosperidade que os grandes centros urbanos despertavam desde a década de 1960, embora tal esperança pareça se destroçar na atualidade em função das transformações socioeconômicas da globalização.

Quem sabe, essa parcela (fora) da sociedade, a população em situação de rua, ao buscar as bibliotecas públicas, queira frequentar esses espaços, pois encontra na internet que lhes é disponibilizada uma extensão da rua, na qual possa "andar"/"vagar" mais longe? Ou por que pode buscar um emprego e, com isso, melhores condições de vida? Quais seriam, portanto, as necessidades informacionais é a pergunta que sempre ressurge, diante das reflexões aqui colocadas. Neste sentido, atribui-se à mediação da informação a possibilidade de que pessoas em situação de rua considerem significado e relevância ao ser competente em informação. E que, ao tomarem consciência de que a "[...] competência desigualmente distribuída e relacionada à origem social, à origem familiar, ao nível cultural e ao nível de educação" (ALMEIDA, 2014, p. 196), isso já seja um passo ou um feixe de luz condutor a uma condição que poderá libertálos da prisão chamada rua.

\section{A mediação da informação como promotora [do resgate] da dignidade e da cidadania}

Compreende-se que há, entre a mediação da informação e a competência em informação, mais que uma proximidade ou diálogo possível, uma complementariedade. Enquanto um processo visa à satisfação das necessidades informacionais das pessoas, o outro busca o desenvolvimento de atividades que possam despertar ou ampliar o senso crítico em relação ao universo informacional, possibilitando-as uma condição de protagonismo social.

Todavia, quando se fala em protagonismo social, Almeida Júnior (2017, p. 53) alerta para que se evite o entendimento dualista desse conceito: 
[...] o protagonismo existe a partir da relação das pessoas com o externo e consigo mesmas; a partir do diálogo delas com a sociedade, com os outros, com o mundo. O protagonismo se faz com o entendimento pessoal e coletivo do mundo; com o conhecimento e reconhecimento que o sujeito tem de si mesmo; com o reconhecimento e entendimento que os outros têm dele, sujeito. $\mathrm{O}$ protagonismo se faz com a presença do sujeito no mundo, com sua compreensão desse mundo, com suas experiências e vivências nesse mundo.

Ainda que o mundo de algumas pessoas possa ser vivido nas e pelas ruas, acredita-se que a condição de vulnerabilidade a que estão expostas é que pode prejudicar ou dificultar o alcance do protagonismo social. Afinal, múltiplas podem ser as vulnerabilidades a que as pessoas podem estar expostas, tais como as econômicas, abarcando-se pessoas desempregadas, rendimentos baixos ou sem meios de sobrevivência, sem habitação; ou as vulnerabilidades culturais, a que estão expostos analfabetos, pessoas com escolaridade baixa, info-excluídos, dentre outros grupos específicos (ARAGÃO, 2011).

Compreende-se que a mediação praticada pelos profissionais da informação, em especial das bibliotecas públicas, deve objetivar também a minimização das múltiplas formas de vulnerabilidade social, incluindo-se exclusão social e vulnerabilidade informacional. Assim, o papel do profissional da informação em relação a comunidades socialmente vulneráveis, ao mediar a informação, por meio de um programa de competência em informação, baseado em necessidades informacionais dos sujeitos, apresenta potencial para fazer evoluir e incrementar a metacompetência nas pessoas " [...] a fim de minimizar os efeitos perversos dos riscos e danos aos quais estão sujeitas no que se refere ao acesso à informação" (VITORINO, 2018, p. 74).

O Serviço de Referência e Informação de boa parte das bibliotecas, em especial as públicas, lamentavelmente trabalha com um conceito de usuário ideal. Tal usuário é construído a partir das ideias dos profissionais bibliotecários em relação às melhores interações dos usuários com os instrumentos técnicos das bibliotecas. O conhecimento das formas de armazenamento, incluindo a ordenação sistemática dos materiais e as entradas de assunto; uma adequada relação com códigos de catalogação; entendimento da linguagem documentária empregada pela biblioteca; o perfeito entendimento das normas para uso dos 
serviços oferecidos, entre outros, fazem parte da figura entendida como usuário ideal. Todo o trabalho interno, os serviços-meio e o trabalho voltado diretamente para o público, têm como base e norte esse usuário. O interesse, a necessidade e o desejo do usuário são também pré-determinados. Qualquer desvio dessa prévia concepção não está contemplado na estrutura dessas bibliotecas. Um grave problema é que esse usuário ideal não é construído em um autêntico estudo de usuário, resumindo-se este em apenas entender se os usuários utilizam ou não, e em que medida os serviços oferecidos. Estudos de usuários, no mais das vezes, resumem-se em investigações sobre usos.

Assim sendo, os analfabetos, por exemplo, estão longe de pertencer ao perfil do usuário ideal. O mesmo ocorre com os que possuem baixa escolaridade e, dentro do interesse deste trabalho, os que vivem em situação de rua. Roupa, higiene, aparência estão fora do que tais bibliotecas entendem como o mínimo requerido para que esses usuários possam fazer uso dos serviços e do acervo. Qualquer ação pressupõe, anteriormente, uma drástica mudança no perfil do usuário, incluindo o tipo de pesquisa e a forma como ele se relaciona com as fontes. Em boa parte das vezes, não estão eles familiarizados com mecanismos de busca que, para nós, que trabalhamos com informação, são de uso cotidiano. A visibilidade dos que vivem em situação de rua deve implicar na inclusão deles entre o grupo entendido como usuário da biblioteca.

Para Vitorino e Piantola (2009, p. 131),“[...] é consenso que [...] o uso consciente, criativo e benéfico da informação tornou-se essencial para a atuação do indivíduo no contexto social contemporâneo". Assim, ter a consciência e a compreensão da finalidade social da informação faz parte dessa nova configuração de sociedade; para tal, o sujeito deve saber a melhor forma de utilizá-la a fim de que gere conhecimento. A partir do momento em que essa consciência e essa compreensão são mediadas, incentivadas e de fato praticadas, coloca-se como probabilidade viável uma participação social menos desigual.

Valentim (2019), ao discorrer acerca das tendências de atuação das bibliotecas e seus profissionais, ancorando-se em relatórios (2013, 2016, 2017, 2018, 2019) da Internacional Federation of Library Associations and Institutions (IFLA), afirma: “[...] o bibliotecário deve chamar para si a responsabilidade, no 
que tange a desenvolver a Competência em Informação (CoInfo) no público ao qual atende" (VALENTIM, 2019, p. 54). A aprendizagem contínua de tais profissionais ajuda a enfrentar transformações requeridas pelos constantes desafios impostos pela inovação tecnológica, e ainda os impactos nos processos de mediação da informação, incluindo a compreensão de novos recursos de mediação (VALENTIM, 2019). Assim, além de exercer o seu papel de protagonista, contribui para o desenvolvimento do protagonismo da comunidade.

Compreende-se a mediação da informação, assim como a competência em informação, "atos de amor", quando ancorados em seus pressupostos conceituais e epistemológicos, podem ser revolucionários e libertadores.

Bezerra (2019), advogando em favor da teoria crítica da informação, integrando os conceitos de regime de informação e o de competência crítica em informação, atribui a esta última um entendimento de emancipação social, uma possibilidade da práxis transformadora. Para o referido autor, a ética dá o norte para a proposição de uma teoria crítica da informação, não sendo meramente filosófica ou intelectual, posto que visa ao "[...] alcance de uma vida melhor, através de maior liberdade e autonomia dos indivíduos”. (BEZERRA, 2019, p. 29). À luz de Freire (2018) que fala da educação como prática da liberdade, em oposição às práticas de dominação, reconhece-se tais "processos" como capazes de individualizar o homem, oportunizá-lo concreto, ligado ao mundo e numa relação com o mundo.

\section{Considerações finais}

Se na rua essas pessoas "são apenas moradores de rua", em um espaço como a biblioteca pública, serão pessoas com nome, com uma história... talvez sem um documento? $\mathrm{O}$ acolhimento dessas organizações públicas, buscando conhecer a necessidade informacional de cada uma delas, que escolheram parte do seu dia para sair da rua, pode indicar que esses espaços informacionais sejam o momento onde podem viver o seu sedentarismo ${ }^{3}$, o seu direito de escolher entre ser um sedentário ou um nômade, já que na rua, um "não-lugar" em que vivem, lhes 
confere uma espécie de invisibilidade que causam transtorno, gera medo, alvo de descaso da sociedade como um todo.

Assim, a mediação da informação, enquanto "[...] ação de interferência realizada em um processo, por um profissional da informação e na ambiência de equipamentos informacionais [...]" (ALMEIDA JÚNIOR, 2015, p. 25), é imprescindível para que se estabeleça quem são essas pessoas, que necessidades informacionais elas carregam? O autor explicita que as nossas necessidades informacionais não são claras, dependendo para tal dos mediadores - no caso deste artigo, dos profissionais da informação que trabalham nas bibliotecas - para que atuem junto às pessoas em situação de rua que a frequentam.

Como população heterogênea, e muito provavelmente sem apoio com o qual essas pessoas se sintam de alguma forma seguras e amparadas, recorre-se à pesquisa de Nascimento (2008, p. 119) que menciona um infortúnio de que são vítimas os trecheiros ${ }^{4}$ : “[...] falta de emprego, potencializada pela desqualificação profissional diante do requintado especialismo e produtivismo do mercado de trabalho". Sendo assim, a mediação da informação, é entendida como um processo que, combinado com outros, dentro de uma biblioteca, tais como a competência em informação, pode contribuir para o resgate da rua, para aqueles que assim o desejarem.

Outrossim, compreende-se que, em espaços como a biblioteca pública, a presença da mediação da informação contribui para o avanço de uma sociedade com habilidades informacionais para formar cidadãos mais críticos e cônscios de sua importância no mundo. Embora pessoas em situação de rua encontrem-se à margem da sociedade - e essa mesma sociedade possa criar mecanismos para que à margem fiquem, em uma visão holística do processo informacional, e do ser humano como um ser aprendente - coloca-se a mediação da informação como elemento de capacidade transformadora, criadora do incentivo ou mesmo efetivação do resgate do eu, aquela que pode gerar o prazer pelo conhecimento, atrelada à busca pela informação e à conquista e/ou resgate da autonomia e da cidadania de pessoas em situação de vulnerabilidade, como o caso das pessoas que vivem na rua, cuja ênfase foi apresentada nas reflexões deste texto. 
Como não se buscou um maior aprofundamento e tampouco houve a intenção de esgotar os temas em foco neste artigo, espera-se que a partir dessas reflexões - lançadas em caráter inicial - outras pesquisas e estudos possam ser incentivados, a fim de trazer contribuições sobre a atuação das bibliotecas públicas como protagonistas junto à população em situação de rua, atendendo à recomendação do Manifesto sobre a Competência em Informação (MANIFESTO..., 2013, p. 1) destacando-se:

Consideramos que o país necessita urgentemente reavaliar suas políticas voltadas às Populações Vulneráveis/Minorias, entendidas como sendo aquelas que se encontram em situações de discriminação, intolerância e fragilidade e que estão em desigualdade e desvantagem na sociedade atual, principalmente, em relação às questões que envolvem o acesso e uso da informação para a construção de conhecimento, identidade e autonomia a fim de permitir a sua efetiva inclusão social.

Esse é o grande desafio!

\section{Referências}

ACRL. Characteristics of programs of information literacy that illustrate best practices: a guideline. Chicago: ACRL, 2012. Disponível em:

http://www.ala.org/acrl/standards/characteristics. Acesso em: 24 ago. 2020.

ACRL. Guidelines for instruction programs in academic libraries. Chicago: ACRL, 2011. Disponível em:

http://www.ala.org/acrl/standards/guidelinesinstruction. Acesso em: 24 ago. 2020.

AGÊNCIA IBGE NOTÍCIAS. Censo é adiado para 2021; coleta presencial de pesquisas é suspensa. Agência IBGE Notícias, Rio de Janeiro, 27 maio 2020. Disponível em: https://agenciadenoticias.ibge.gov.br/agencia-noticias/2012agencia-de-noticias/noticias/27160-censo-e-adiado-para-2021-coleta-presencialde-pesquisas-e-suspensa. Acesso em: 23 fev. 2021.

ALMEIDA JÚNIOR, O. F. Ação cultural e protagonismo social. In: GOMES, H. F.; NOVO, H. F. Informação e protagonismo social. Salvador: EDUFBA, 2017. p. $45-58$.

ALMEIDA, M. A. Mediação e mediadores nos fluxos tecnoculturais contemporâneos. Informação \& Informação, Londrina, v. 19, n. 2, p. 191-214, maio/ago. 2014. 
ALMEIDA JÚNIOR, O. F. Mediação da informação: um conceito atualizado. In: BORTOLIN, S.; SANTOS NETO, J. A.; SIVAL, R. J. (org.). Mediação oral da informação e da leitura. Londrina: Abecin, 2015. p. 9-32.

ALMEIDA, S. F. de. População em situação de rua e o retorno à educação escolar: entre dificuldades e possibilidades. In: CONGRESSO INTERNACIONAL DE PEDAGOGIA SOCIAL, 4., 2012, São Paulo. Proceedings [...]. São Paulo: Associação Brasileira de Educadores Sociais, 2012. p. 1-22.

AQUINO, M. de A. Políticas de informação para inclusão de negros afrodescendentes a partir de uma nova compreensão da diversidade cultural. Inclusão Social, Brasília, v. 3, n. 2, p. 26-37, jan./jun. 2010

ARAGÃO, A. Prevenção de riscos na União Europeia: o dever de tomar em consideração a vulnerabilidade social para uma protecção civil eficaz e justa. Revista Crítica de Ciências Sociais, Coimbra, n. 93, p. 71-93, 2011. Disponível em: http://rccs.revues.org/174. Acesso em: 09 fev. 2020.

AUSUBEL, D. P. A aprendizagem significativa: a teoria de David Ausubel. São Paulo: Moraes, 1982.

BELLUZZO, R. C. B. A competência em informação no Brasil: cenários e espectros. São Paulo: ABECIN, 2018. E-book.

BELLUZZO, R. C. B.; SANTOS, C. A.; ALMEIDA JÚNIOR, O. F. A competência em informação e sua avaliação sob a ótica da mediação da informação: reflexões e aproximações teóricas. Informação \& Informação, Londrina, v. 19, n. 2, p. 60-77, maio/ago. 2014.

BEZERRA, A. C. Teoria crítica da informação: proposta teórico-metodológica de integração entre os conceitos de regime de informação e competência crítica em informação. In: BEZERRA, A. C.; SCHNEIDER, M.; PIMENTA, R. M.; SALDANHA, G. S. iKrítica: estudos críticos em informação. Rio de Janeiro: Garamond, 2019. p. 15-72.

BRASIL. Decreto no 7.053 de 23 de dezembro de 2009. Institui a Política Nacional para a População em Situação de Rua e seu Comitê Intersetorial de Acompanhamento e Monitoramento, e dá outras providências. Brasília: Presidência da República, 2009. Disponível em: http://www.planalto.gov.br/ccivil_03/_ato2007-2010/2009/decreto/d7053.htm. Acesso em: 23 fev. 2021.

BRASIL. Ministério da Saúde. Secretaria de Gestão Estratégica e Participativa. Saúde da população em situação de rua: um direito humano. Brasília: Ministério da Saúde, 2014. Disponível em: 
http://bvsms.saude.gov.br/bvs/publicacoes/saude_populacao_situacao_rua.pdf. Acesso em: 23 fev. 2021.

BRUCE, C. S. Las siete caras de la alfabetización en información em la enseñanza superior. Anales de Documentación, Múrcia, n. 6, p. 289-294, 2003.

BURTON, G. Teorizando o Estado e a Globalização na política e políticas educacionais. Revista Práxis Educativa, Ponta Grossa, v. 9, n. 2, p. 315-331, jul./dez. 2014.

CATTS, R.; LAU, J. Towards information literacy indicators. UNESCO: Paris, 2008. Disponível em: origin-www.ifla.org/files/assets/informationliteracy/publications/towards-information-literacy_2008-en.pdf. Acesso em: 24 ago. 2020.

CERQUIER-MANZINI, M. L. O que é cidadania. 4. ed. São Paulo: Brasiliense, 2013.

CORRÊA, E. Usuário, não! Interagente. Proposta de um novo termo para um novo tempo. Encontros Bibli: Revista Eletrônica de Biblioteconomia e Ciência da Informação, Florianópolis, v. 19, n. 41, p. 23-40, dez. 2014.

COSTA, A. P. M. População em situação de rua: contextualização e caracterização. Revista Virtual Textos \& Contextos, Porto Alegre, n. 4, v. 1, p. 1-15, dez. 2005.

CUNHA, J. V. Q. da; RODRIGUES, M. (org.). Rua: aprendendo a contar: pesquisa nacional sobre a população em situação de rua. Brasília: Ministério do Desenvolvimento Social e Combate à Fome, 2009. Disponível em: http://www.mds.gov.br/webarquivos/publicacao/assistencia_social/Livros/Rua_ aprendendo_a_contar.pdf. Acesso em: 22 fev. 2021.

CUNHA, M. V. O papel social do bibliotecário. Encontros Bibli: Revista eletrônica de Biblioteconomia e Ciência da Informação, Florianópolis, v. 8, n. 15, p. 41-46, 2003.

FREIRE. P. Pedagogia da autonomia: saberes necessários à prática educativa. Rio de Janeiro: Paz e Terra, 2011.

FREIRE, P. Pedagogia do oprimido. Rio de Janeiro: São Paulo: Paz e Terra, 2018.

FREITAS, C. J. "Os indesejáveis": agentes públicos e a gestão da mobilidade de trecheiros e pessoas em situação de rua. 2014. Dissertação (Mestrado em Psicologia) - Faculdade de Ciências e Letras de Assis, Universidade Estadual Paulista, Assis, 2014. 
GOMES, H. F. A dimensão dialógica, estética, formativa e ética da mediação da informação. Informação \& Informação, Londrina, v. 19, n. 2, p. 46-59, maio/ago. 2014.

GONZÁLEZ DE GÓMEZ, M. N. Desafios contemporâneos da Ciência da Informação: as questões éticas da informação. In: ENCONTRO NACIONAL DE PESQUISA DA ASSOCIAÇÃO NACIONAL DE PESQUISA E PÓSGRADUAÇÃO EM CIÊNCIA DA INFORMAÇÃO, 10., 2009, João Pessoa. Anais [...]. João Pessoa: UFPB, 2009. p. 106-126.

JUSTO, J. S. et al. Políticas públicas de mobilidade e assistência a itinerantes: o caso dos trecheiros. Emancipação, Ponta Grossa, v. 13, n. 3, p. 105-120, 2013.

KUHLTHAU, C. C. Information search process. New Brunswick, NJ: Rutgers School of Communication and Information, 2018. Disponível em: http://wp.comminfo.rutgers.edu/ckuhlthau/information-search-process/. Acesso em: 24 ago. 2020.

LINN, L. S.; GELBERG, L. Priority of basic needs among homeless adults. Social Psychiatry and Psychiatric Epidemiology, [s. l.], v. 24, n. 1, p. 23-29, 1989.

MANIFESTO de Florianópolis sobre a competência em informação e as populações vulneráveis e minorias. In: SEMINÁRIO COMPETÊNCIA EM INFORMAÇÃO: CENÁRIOS E TENDÊNCIAS, 2., 2013, Florianópolis. Anais [...]. Florianópolis: FEBAB, 2013. p. 1-3. Disponível em: http://repertorium.marilia.unesp.br:8180/handle/123456789/231. Acesso em: 23 fev. 2021.

NASCIMENTO, E. C. Nomadismos contemporâneos: um estudo sobre errantes trecheiros. São Paulo: UNESP, 2008.

NATALINO, M. A. C. Estimativa da população em situação de rua no Brasil. Rio de Janeiro: IPEA, 2016. (Texto para Discussão, n. 2246). Disponível em:

https://www.ipea.gov.br/portal/images/stories/PDFs/TDs/26102016td_2246.pdf. Acesso em: 23 fev. 2021.

SANTOS, M. Por uma outra globalização: do pensamento único à consciência universal. 12. ed. Rio de Janeiro: Record, 2005.

SANTOS, R. N. R dos; LIMA, G. B. de; FREIRE, I. M. Interfaces sociais da Ciência da Informação: competência em informação por pessoas LGBTI+. In: FARIAS, G. B. de; FARIAS, M. G. G. (org.). Competência e mediação da informação: percepções dialógicas entre ambientes abertos e científicos. São Paulo: ABECIN, 2019. p. 130-145. 
TELLO, F. M. Servicios bibliotecarios para grupos vulnerables: la perspectiva em las directrices de la IFLA y otras asociaciones. Informação \& Sociedade: estudos, João Pessoa, v. 18, n. 1, p. 45-66, jan./abr. 2008.

TORRES, T. Morador de rua passa dia em biblioteca lendo e anotando, para matar dor do tempo. Campo Grande News, Campo Grande, 28 jul. 2016. Disponível em: https://bit.ly/2NND0XZ. Acesso em: 2 mar. 2021.

UNICEF. The state of the world's children 2017: children in a Digital World. New York City: UNICEF, 2017.

VALENTIM, M. L. P. Tendências e perspectivas profissionais e as competências essenciais para a formação e a atuação do bibliotecário. Revista Eletrônica da ABDF, Brasília, v. 3, n. 2, p. 46-63, jul./dez. 2019.

VELHO, G.; KUSCHNIR, K. (org.). Mediação, cultura e política. Rio de Janeiro: Aeroplano Editora, 2001.

VIEIRA, M. A. C.; BEZERRA, E. M. R.; ROSA, C. M. M. População de rua: quem é, como vive, como é vista. São Paulo: Hucitec, 1994.

VITORINO, E. V. A competência em informação e a vulnerabilidade: construindo sentidos à temática da "vulnerabilidade em informação". Ciência da Informação, Brasília, v. 47, n. 2, p. 71-85, maio/ago. 2018.

VITORINO, E. V.; PIANTOLA, D. Competência informacional - bases históricas e conceituais: construindo significados. Ciência da Informação, Brasília, v. 38, n. 3, p. 130-141, set./dez. 2009.

VITORINO, E. V.; PIANTOLA, D. Dimensões da competência informacional. Ciência da Informação, Brasília, v. 40, n. 1, p. 99-110, jan./abr. 2011.

\title{
The mediation of information in the rescue of visibility and dignity of vulnerable: the case of homeless people
}

\begin{abstract}
The mediation of information is debated under the social vulnerability perspective, considering as information citizen the homeless people. The question is if this population, besides not having the basic needs guaranteed by the government, will have their necessities provided by the information professionals. Therefore, the objective is to reflect about the mediation of information as promoter in the rescue of citizenship and dignity for vulnerable people, in the public library spaces. It's a qualitative study, from literature review of catalogues from public universities and CAPES journal involving topics like: mediation of information, social vulnerability, homeless people, information literacy and public library. Perceived as a process that, with the information literacy, has the
\end{abstract}


change potential to give the people the information empowerment, that can minimize the poverty condition, and mainly the multiples vulnerabilities that they are exposed to. It is understood that the information professionals from public libraries are mediators able to contribute to the vulnerable people to attend to these places, giving them the right to access information, making it possible, even for a short period, and for many reasons, to live the sedentarism that they can not have. In places like a public library, the presence of mediation of information contributes for the society development with information skills, forming this way more critical citizens with self-conscious about its importance in the world.

Keywords: Mediation of information. Homeless people. Information Literacy. Social Vulnerability. Public Library.

Recebido: $25 / 04 / 2020$

Aceito: $28 / 08 / 2020$

\section{Declaração de autoria}

Concepção e elaboração do estudo: Tânia Regina de Brito, Regina Célia Baptista Belluzzo, Oswaldo Francisco de Almeida Junior

Coleta de dados: Tânia Regina de Brito, Regina Célia Baptista Belluzzo, Oswaldo Francisco de Almeida Junior

Análise e discussão de dados: Tânia Regina de Brito, Regina Célia Baptista Belluzzo, Oswaldo Francisco de Almeida Junior

Redação e revisão do manuscrito: Tânia Regina de Brito, Regina Célia Baptista Belluzzo, Oswaldo Francisco de Almeida Junior

\section{Como citar}

BRITO, Tânia Regina de; BELLUZZO, Regina Célia Baptista; ALMEIDA JUNIOR, Oswaldo Francisco de Almeida. A mediação da informação no resgate da visibilidade e dignidade dos vulneráveis: o caso das pessoas em situação de rua. Em Questão, Porto Alegre, v. 27, n. 2, p. 323-345, abr./jun. 2021.

Doi: http://dx.doi.org/10.19132/1808-5245272.323-345

1 Trata-se da cidade de Campo Grande-MS e do jornal Campo Grande News que no dia 28 de julho de 2016 noticiou com a manchete: "Morador de rua passa dia em biblioteca e anotando, para matar dor do tempo" (TORRES, 2016).

2 Para Freitas (2014), a diferença entre trecheiros e pessoas em situação de rua é o grau de deambulação. Enquanto os últimos são capazes de permanecer por longo tempo em certos lugares da rua até serem retirados à força ou sob algum tipo de pressão, os primeiros, mesmo que não passem por situações de repressão como as pessoas em situação de rua, em algum momento, mesmo após permanecerem por um período em determinada cidade, são compelidos a continuarem a caminhada, a pé ou mediante concessão de passagens de ônibus. Assim, identifica-se por pesquisas iniciais que são consideradas populações itinerantes, sendo identificados casos de espancamento, ameaças e assassinato entre elas, considerando-se por isso, 
a vulnerabilidade de ambas. Para Justo et al. (2013), os trecheiros são considerados pessoas em situação de rua, no entanto com práticas distintas de outros nomadismos.

${ }^{3}$ Os autores deste artigo entendem que não existe certo ou errado em viver o nomadismo ou o sedentarismo, não sendo o termo empregado de forma pejorativa, mas entendendo que fazem parte "[...] dos estudos sociais acerca do homem na sociedade contemporânea" (NASCIMENTO, 2008, p. 11).

${ }^{4}$ Salienta-se que esse tipo de população também é mencionada como sendo população em situação de rua por Justo et al. (2013), conforme mencionado anteriormente e, por esse motivo foi considerada aqui. 